\title{
Statistical analysis on spatial correlation of ionospheric day-to-day variability by using GPS and Incoherent Scatter Radar observations
}

\author{
X. Yue ${ }^{1,2,3}$, W. Wan ${ }^{1}$, L. Liu ${ }^{1}$, and T. Mao ${ }^{1,2,3}$ \\ ${ }^{1}$ Institute of Geology and Geophysics, Chinese Academy of Sciences, Beijing 100029, China \\ ${ }^{2}$ Wuhan Institute of Physics and Mathematics, Chinese Academy of Sciences, Wuhan 430071, China \\ ${ }^{3}$ Graduate School, Chinese Academy of Sciences, Beijing 100049, China
}

Received: 22 March 2007 - Revised: 12 July 2007 - Accepted: 3 August 2007 - Published: 29 August 2007

\begin{abstract}
In this paper, the spatial correlations of ionospheric day-to-day variability are investigated by statistical analysis on GPS and Incoherent Scatter Radar observations. The meridional correlations show significant $(>0.8)$ correlations in the latitudinal blocks of about 6 degrees size on average. Relative larger correlations of TEC's day-to-day variabilities can be found between magnetic conjugate points, which may be due to the geomagnetic conjugacy of several factors for the ionospheric day-to-day variability. The correlation coefficients between geomagnetic conjugate points have an obvious decrease around the sunrise and sunset time at the upper latitude $\left(60^{\circ}\right)$ and their values are bigger between the winter and summer hemisphere than between the spring and autumn hemisphere. The time delay of sunrise (sunset) between magnetic conjugate points with a high dip latitude is a probable reason. Obvious latitude and local time variations of meridional correlation distance, latitude variations of zonal correlation distance, and altitude and local time variations of vertical correlation distance are detected. Furthermore, there are evident seasonal variations of meridional correlation distance at higher latitudes in the Northern Hemisphere and local time variations of zonal correlation distance at higher latitudes in the Southern Hemisphere. These variations can generally be interpreted by the variations of controlling factors, which may have different spatial scales. The influences of the occurrence of ionospheric storms could not be ignored. Further modeling and data analysis are needed to address this problem. We suggest that our results are useful in the specific modeling/forecasting of ionospheric variability and the constructing of a background covariance matrix in ionospheric data assimilation.
\end{abstract}

Keywords. Ionosphere (Ionospheric disturbances; Modeling and forecasting, Solar radiation and cosmic ray effects)

Correspondence to: W. Wan

(wanw@mail.iggcas.ac.cn)

\section{Introduction}

It is now well known that the ionosphere displays both a background state (climatology) and a disturbed state (weather). These variations cover a wide range of time scales, which range from operational time scales of hours and days up to solar cycles and even long-term trends (Rishbeth, 1998). Among these variabilities with different time scales, day-to-day variability is one of the most frequently investigated recently for both scientific and applicable reasons (Forbes et al., 2000; Fuller-Rowell et al., 2000; Mendillo et al., 2002; Rishbeth and Mendillo, 2001). Bradley et al. (2002) have given a detailed explanation of the terminology variability. Most of the ionospheric characteristic parameters' day-to-day variability, including $f o \mathrm{~F} 2, h m \mathrm{~F} 2, f o \mathrm{~F} 1$, $f o \mathrm{E}, \mathrm{B} 0$, and $\mathrm{B} 1$, have been studied by using ionosonde observations from single, regional, or global stations (Dabas et al., 2006; Araujo-Pradere et al., 2005; Fotiadis and Kouris, 2006). This research give us a general variation of ionospheric variability versus solar radiation, geomagnetic activity, latitude, and local time. Furthermore, Bradley et al. (2004) and Miro Amarante et al. (2004) even investigated the day-to-day variability of electron density profiles. Except for statistical analysis, Fuller-Rowell et al. (2000) and Mendillo et al. (2002) have modeled the ionospheric variability response to geomagnetic activity and meteorological disturbances quantitatively, using different theoretical models, respectively.

However, most research related to day-to-day variability in the past concentrated on its variations with local time, latitude, solar and geomagnetic activity, and attempted to give corresponding physical explanations. The spatial correlation scales of these variabilities have rarely been investigated systematically (at least to our knowledge up to now), except for Bradley et al. (2004), who have investigated the correlations of the variabilities of different parameters. The spatial correlation is a measure of how well a deviation at

Published by Copernicus Publications on behalf of the European Geosciences Union. 
one point is mirrored at a remote point. Perfectly correlated data will have correlation coefficients equal to 1, dropping to 0 for no correlation between the data, and -1 for perfect anti-correlation. The horizontal correlation of ionospheric climatology has been studied by several researchers using ionosonde, GPS, and TOPEX observations (Bust et al., 2001; Gail et al., 1993; Huang, 1983; Klobuchar et al., 1995; Nisbet et al., 1981; Rush, 1976; Saito, 1978). But most of these papers investigated the horizontal correlation of the mid-latitude area. Few investigations are related to the ionospheric vertical correlation. Furthermore, the spatial correlation of different time scales in ionosphere may have differences, as they have different causes. Yu et al. (2007) have investigated the correlation distance of $N m \mathrm{~F} 2$ 's dayto-day variability by using ionosonde observations in Europe. But their conclusions can only be applied to the midlatitude. In this paper, we will investigate the spatial correlation including both the horizontal and vertical correlation of ionospheric day-to-day variability systematically by statistical analysis on GPS and Incoherent Scatter Radar observations on a global scale. There are also several other reasons for us to implement this work as follows. (1) Ionospheric weather can have detrimental effects on several human activities and systems, including high-frequency communications, over-the-horizon radars, and survey and navigation systems using Global Positioning System (GPS) satellites. To avoid the destructive effects of ionosphere weather on military and civilian systems, there is a growing need to more accurately represent and forecast the ionosphere. According to Nisbet et al. (1981), it would be necessary to include some measure of the ionosphere's day-to-day variability to obtain a more accurate prediction of the ionosphere. They found that the data within $1000 \mathrm{~km}$ of the point to be predicted were useful for the prediction. Beyond $3000 \mathrm{~km}$ the accuracy of the updated model was found to be no better than the predictions made using the model alone. Actually, here the $1000 \mathrm{~km}$ or $3000 \mathrm{~km}$ is related to the spatial correlation distance of the ionosphere. So it is important for us to know exactly the variation of the ionospheric spatial correlation of day-to-day variability versus many factors, such as latitude and local time, to give a more accurate prediction of ionospheric weather. Furthermore, the scale factor (SF), which is frequently used in ionosphere mapping, is also correlated with the ratio of zonal correlation distance to the meridional correlation distance (Stanislawska et al., 1996). (2) Recently, many researchers attempt to incorporate observations and ionospheric models by using optimization schemes, known as the data assimilation method, to give specific representation of the ionosphere (Bust et al., 2004; Fuller-Rowell et al., 2006). When doing the data assimilation, especially based on the empirical model, an accurate correlation model of the ionosphere is very important (Bust et al., 2004; Fuller-Rowell et al., 2006). It determines the extent of data influence on regions where there is no data. (3) According to Rishbeth and Mendillo (2001), there are many causes that can result in the day-to-day variability of the ionosphere. A better knowing of the ionospheric correlation distance of these variabilities may help us to understand the spatial scale of different causes.

The remainder of this paper is organized as follows. Section 2 describes the data source and analysis method. The results are given in Sect. 3. We give our discussions and conclusions in Sects. 4 and 5.

\section{Data source and analysis method descriptions}

In this paper, we assume that the spatial correlations of the ionosphere are separable meridionally, zonally and vertically, as Bust et al. (2004) did. We use GPS-TEC to investigate the horizontal correlation of the ionosphere. The TEC value used here is the Jet Propulsion Laboratory Global Ionospheric Map (JPL GIM). Mannucci et al. (1998) and Iijima et al. (1999) have described the method and process of retrieving the grid vertical TEC from global GPS measurements in detail. They used the Kalman filter to simultaneously solve for the values of hardware biases and the vertical TEC map. From the many IGS stations available, up to 100 stations are selected to optimize geographic coverage. With the increase in the number of IGS stations, the selected stations are not fixed. So we could not show the exact GPS stations used here. The vertical TEC data provided are between geographical latitude $-87.5^{\circ}$ and $87.5^{\circ}$ with an interval of $2.5^{\circ}$, and between geographical longitude $-180^{\circ}$ and $180^{\circ}$ with an interval of $5^{\circ}$. As we know, the ionospheric electron density is more symmetrical in geomagnetic coordinates than in geographical coordinates. So we first transform the data in a geographical reference frame to apex magnetic coordinates by interpolation (Richmond, 1995). According to Mannucci et al. (1998), the GIM products have relatively larger errors in high latitudes and ocean areas because of less coverage. So we just used the data between the apex magnetic latitude $-60^{\circ}$ and $60^{\circ}$. It should be pointed out that GIM data errors associated with the thin spherical shell assumption, the data interpolation, and the insufficient station coverage in ocean areas, may affect the statistical results. By comparison with TOPEX TEC, the daily RMS accuracy of GIM TEC maps has been better than 10 TECU. Accuracy has been better than 5 TECU in the months where the TEC was low (Iijima et al., 1999). But the error may be smaller inland because of better data coverage there.

The Millstone Hill $\left(42.6^{\circ} \mathrm{N}, 288.5^{\circ} \mathrm{E}\right.$; $72^{\circ} \mathrm{N}$ Dip) Incoherent Scatter Radar observed electron densities from 4 October to 4 November 2002, are used to study the vertical correlation of the ionosphere. The profiles are fitted by the two-layer Chapman function (Fox, 1994). The fit method used here is focused on the F2-layer. So it may have a relatively bad performance when the profile in the topside ionosphere demonstrates an inflection point or a second peak or when the F1 layer exists (Fox, 1994). Then we calculate the 

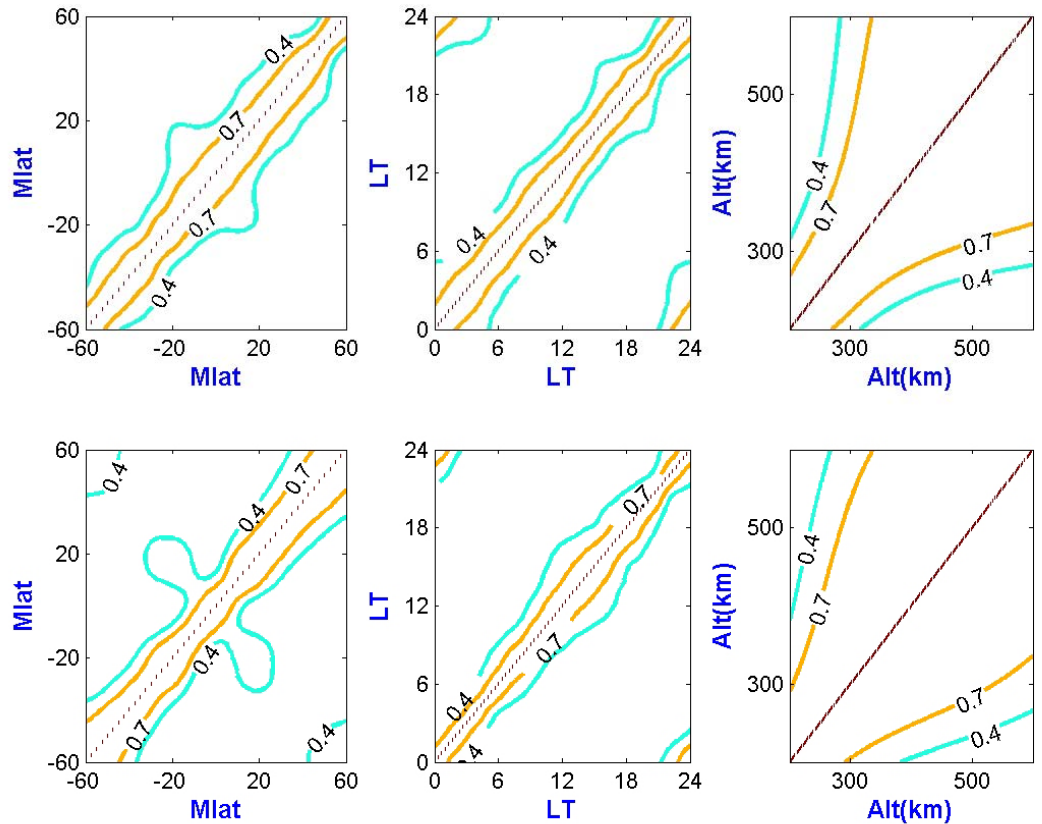

Fig. 1. Correlation coefficients' sketch map. From left to right panels are meridional, zonal, and vertical correlation coefficients, respectively. Meridional correlation coefficients are shown between mlat $-60^{\circ}-60^{\circ}$, and the top and bottom panel corresponds to night and day time. Zonal correlation coefficients are shown between different local times, and the top and bottom panels are for mlat $40^{\circ}$ and $0^{\circ}$, respectively. Vertical correlation coefficients are shown between $200-600 \mathrm{~km}$, and the top and bottom panels are for night and day time, respectively.

electron densities between $200-600 \mathrm{~km}$ with an interval of $2 \mathrm{~km}$ by the fitted coefficients.

To calculate the correlations of $\mathrm{N}$ variables in a vector $\varphi$, we first construct a matrix consisting of different samples of $\varphi$. Then the variance covariance matrix of the sample matrix is obtained. The correlation coefficient can then be calculated from the covariance element. The processes are represented by the equations:

$$
\begin{aligned}
& A=\left(\varphi_{1}, \varphi_{2}, \ldots, \varphi_{m}\right) \in R_{N \times m} \\
& A^{\prime}=A-\bar{A} \\
& P=\frac{A^{\prime}\left(A^{\prime}\right)^{T}}{m-1} \\
& R_{i j}=\frac{P_{i j}}{\sqrt{P_{i i} P_{j j}}},
\end{aligned}
$$

where $A$ is the sample matrix of vector $\varphi, \bar{A}$ is the sample mean of $A, P$ is the variance covariance matrix of $A$, and $R_{i j}$ is the correlation coefficient between variables $\mathrm{i}$ and $\mathrm{j}$ in vector $\varphi$. The correlation coefficients of electron densities are derived as follows. At first, the day-to-day variabilities of TEC and electron densities are calculated by differencing them with their corresponding value from the previous day. For TEC, we chose the data of 2000 and 2005 to represent high and low solar activities, respectively. According to Araujo-Pradere et al. (2004), it may be useful to introduce intermediate seasons between winter or summer solstices and the equinox, in the seasonal variation analysis of the ionospheric variability. But in our work, the statistical results depend on the sample numbers. The addition of a season means relativly less days in each season. So the data are divided into four samples, which correspond to the interval of FebruaryApril, May-July, August-October, and November-January, respectively, in every year in this work. The horizontal correlations are calculated for the eight samples, respectively, to investigate their solar and season variations. But for vertical correlations, only one sample is used here. The longitudinal effects are ignored when calculating both meridional and zonal correlations. Then the correlation coefficients are obtained for the three directions, respectively.

\section{Results}

\subsection{Correlation coefficients' sketch map}

Typical correlation coefficients of three directions are shown in Fig. 1. According to the figure, both meridional and vertical correlations have differences between day time and night. The meridional correlations show significant $(>0.8)$ correlation in the latitudinal blocks of about 6 degrees on average. Relatively larger correlations can be found between the magnetic conjugate points. Furthermore, the vertical correlation has obvious altitude dependence. In the following, we will give detailed results about these variations of the correlations versus different factors, including local time, latitude, altitude, and season. 


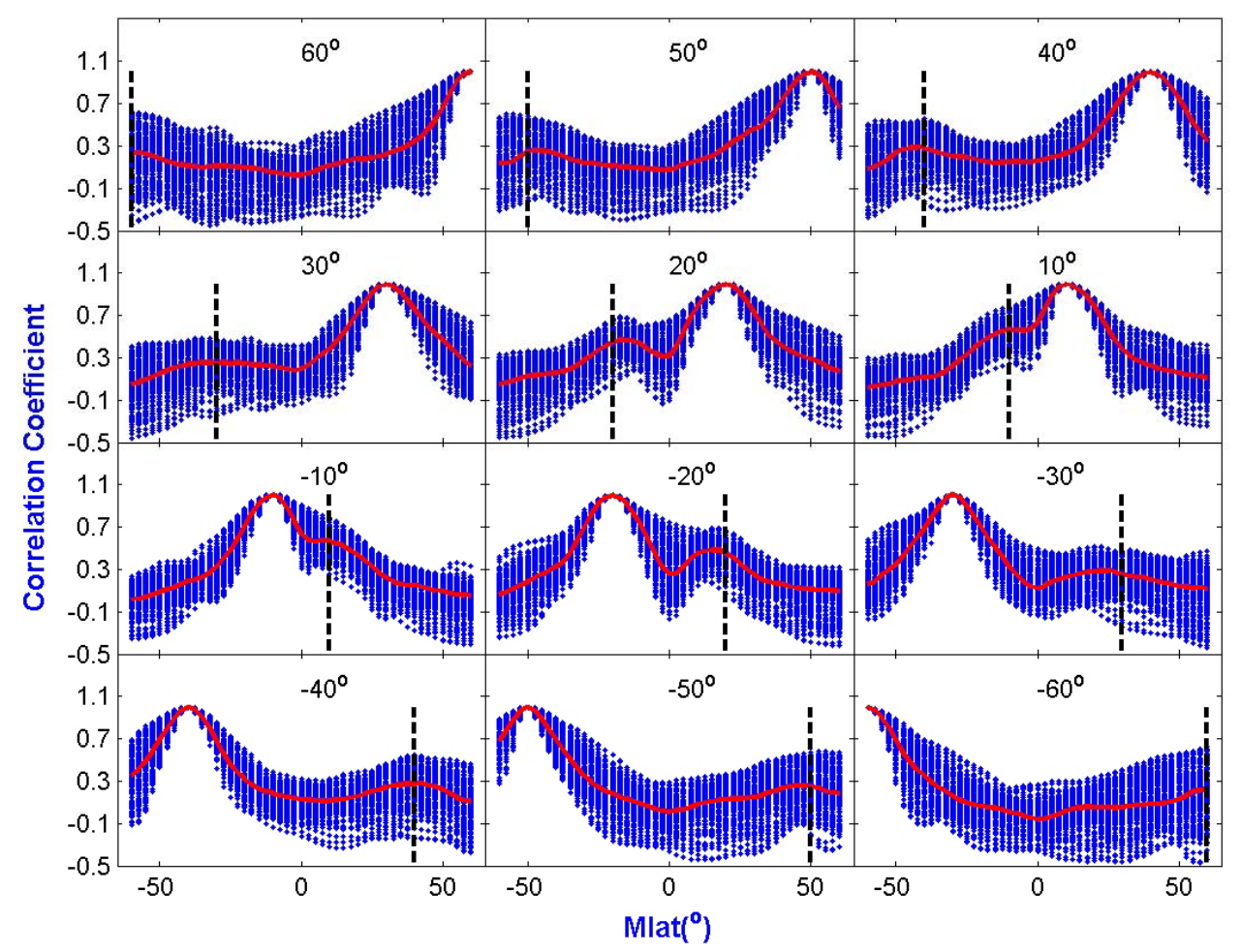

Fig. 2. (a) Correlation coefficients between one fixed apex latitude with all other apex latitudes from $-60^{\circ}$ to $60^{\circ}$. The number in every subplot is the corresponding apex latitude. The solid lines are mean values of different local time, month and year. The vertical dashed lines mark the corresponding magnetic conjugate latitude.

\subsection{Correlation between magnetic conjugate points}

Before illustrating the correlation coefficients results, it is important for us to know exactly which level of correlation coefficient is significant or strong. As Bradley et al. (2004) said, there is no consensus as to what represents significant or a highly significant correlation, with some arguing that there is only interest in occasions with $\mathrm{R}>0.9$. In this paper, we will follow their opinion and do not say significant when the correlation coefficient is less than 0.9 . Relatively larger correlations can be found between magnetic conjugate points from the isoline map of meridional correlation, especially during the daytime. Figure $2 \mathrm{a}$ shows the correlation coefficients between one fixed apex latitude with all other apex latitudes from $-60^{\circ}$ to $60^{\circ}$. The number in every subplot is the corresponding apex latitude. The solid lines are mean values of different local time, month and year. The vertical dashed lines mark the corresponding magnetic conjugate latitude. The correlation coefficients between one fixed apex latitude and the field near its conjugate latitude have obvious protuberance. Figure $2 \mathrm{~b}$ shows the local time variations of the correlation coefficients between magnetic conjugate points during the interval of February-April, MayJuly, August-October, and November-January, respectively. With the increase in latitude, the local time variations be- come more evident. The correlation coefficients between $60^{\circ}$ and $60^{\circ}$ have an obvious decrease in sunrise and sunset time. During the interval of May-July and NovemberJanuary, even negative correlations can be found between $60^{\circ}$ and $60^{\circ}$ near sunrise and sunset. In the main, the correlation coefficients between conjugate points are bigger during the interval of February-April and August-October than May-July and November-January, which means the correlations between conjugate points are greater in the equinoxes than in the solstices.

\subsection{Meridional correlation distance}

In this paper, the correlation distance is defined as the separation at which the correlation coefficient falls to 0.75 . The horizontal and vertical correlation distances are represented by degree and kilometer, respectively. The latitude, local time, and seasonal variations of the meridional correlation distance are shown in Fig. 3. According to the figure, we can obtain several conclusions. There are no evident latitude variations of the meridional correlation distance around midnight. The mean value is between $7^{\circ}$ and $8^{\circ}$. In the daytime, the meridional correlation distance is bigger in the mid-latitude than in the low and equatorial latitudes and the value varies from $10^{\circ}$ in mid-latitude to $5^{\circ}$ in the equatorial area. However, 


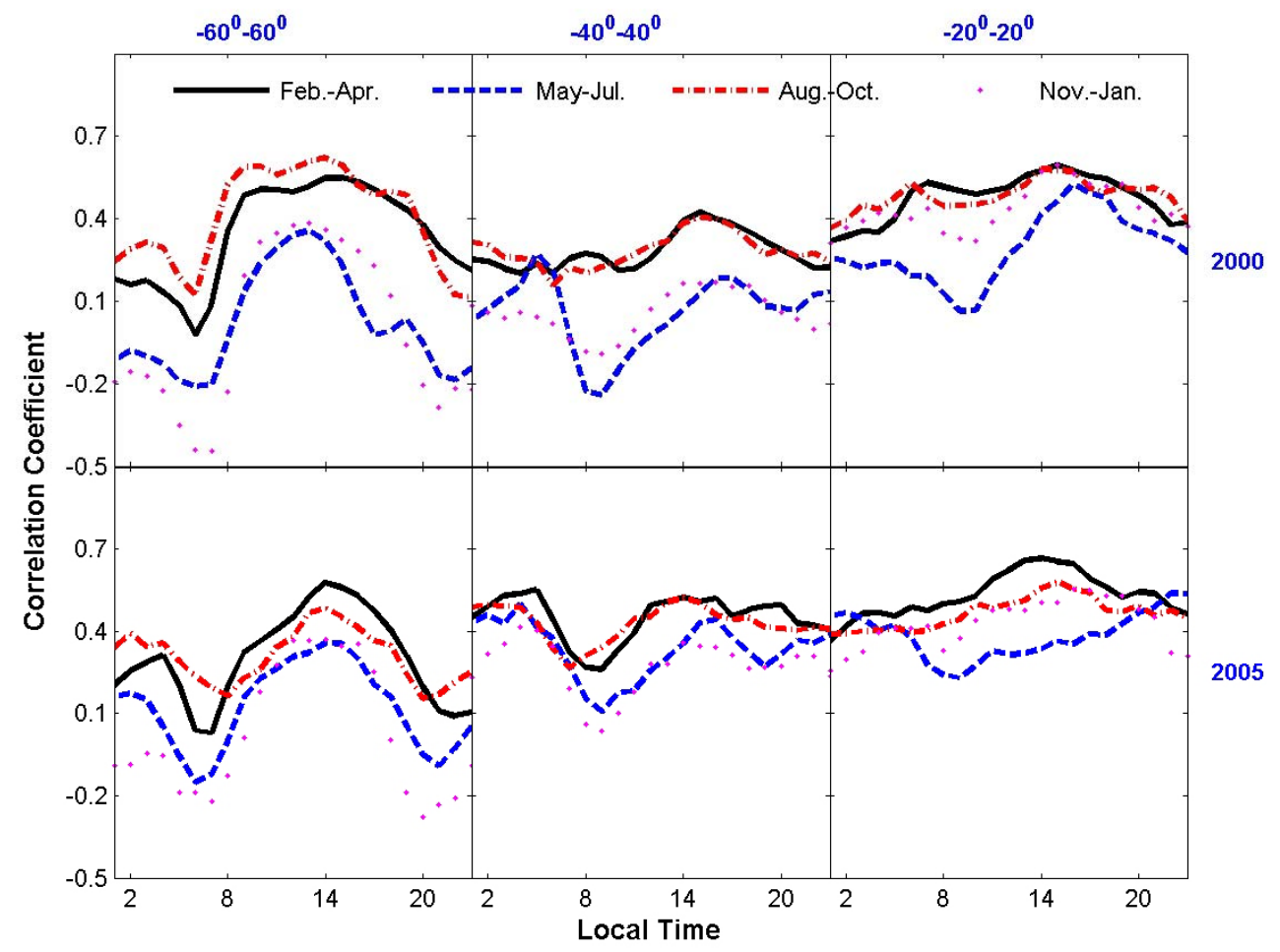

Fig. 2. (b) Local time variations of the correlation coefficients between magnetic conjugate points for the interval of February-April (solid lines), May-July (dashed lines), August-October(dashdot lines), and November-January (dots), respectively. The panels from left to right are for the magnetic conjugate points $-60^{\circ}-60^{\circ},-40^{\circ}-40^{\circ},-20^{\circ}-20^{\circ}$, respectively. The top panel is the situation of year 2000 , while the bottom for 2005 .

around sunrise (from $\mathrm{LT}=3$ to $\mathrm{LT}=9$ ), the meridional correlation distance is larger in the equatorial area than in the midlatitude, whose mean value varies from $11^{\circ}$ to $5^{\circ}$. For all the selected latitudes, the meridional correlation distance is larger in the daytime than in the nighttime, which is consistent with that of Yu et al. (2007). The mean value is between $5^{\circ}$ and $15^{\circ}$. Except for areas around the equator (from $20^{\circ}$ to $20^{\circ}$ ), where the max meridional correlation distance of a day appears around sunrise, the maximum always arises in the afternoon (around LT=14). In the mid-latitude of the Northern Hemisphere (from $40^{\circ}$ to $60^{\circ}$ ), the meridional correlation distance is larger in summer than in equinox and larger in equinox than in winter. Yu et al. (2007) also obtained the same seasonal variations from ionosonde observations in Europe. But for the rest of the latitudes, no obvious season variations can be found.

\subsection{Zonal correlation distance}

In this paper, the zonal correlation distance is defined as the east-west separation at which the correlation coefficients falls to 0.75 . Local time variations of the zonal correlation distance for the selected latitudes during different seasons are shown in Fig. 4. It is seen that the zonal correlation distance increases with the increase in latitude in both hemispheres.
The mean value varies from $40^{\circ}$ in the mid-latitude (absolute latitude is equal to $60^{\circ}$ ) to $20^{\circ}$ in the equator. Except in the mid-latitude of the South Hemisphere (between $-60^{\circ}$ and $-40^{\circ}$ ), where the zonal correlation distance is larger in the nightside than in the dayside, there are no distinct local time variations in the rest area. The same holds true for the zonal correlation distance as meridional correlation distance; the zonal correlation distance is little larger in summer than in the other seasons in the mid-latitude of the North Hemisphere (from $40^{\circ}$ to $60^{\circ}$ ). In general, the value of the zonal correlation distance is larger than that of the meridional correlation distance. These differences in correlation distance in the north-south and east-west direction are also recognized by many others (Rush et al., 1976).

\subsection{Vertical correlation distance}

Altitude and local time variations of the vertical correlation distance are plotted in Fig. 5. When illustrating the altitude variations, all the results in the different local times are plotted together and the mean values are calculated. The vertical correlation distance increases with an increase in altitude. The mean value varies from $75 \mathrm{~km}$ in $200 \mathrm{~km}$ altitude to $240 \mathrm{~km}$ in the $600 \mathrm{~km}$ altitude. According to the local time variations of the mean values in the different altitudes, 


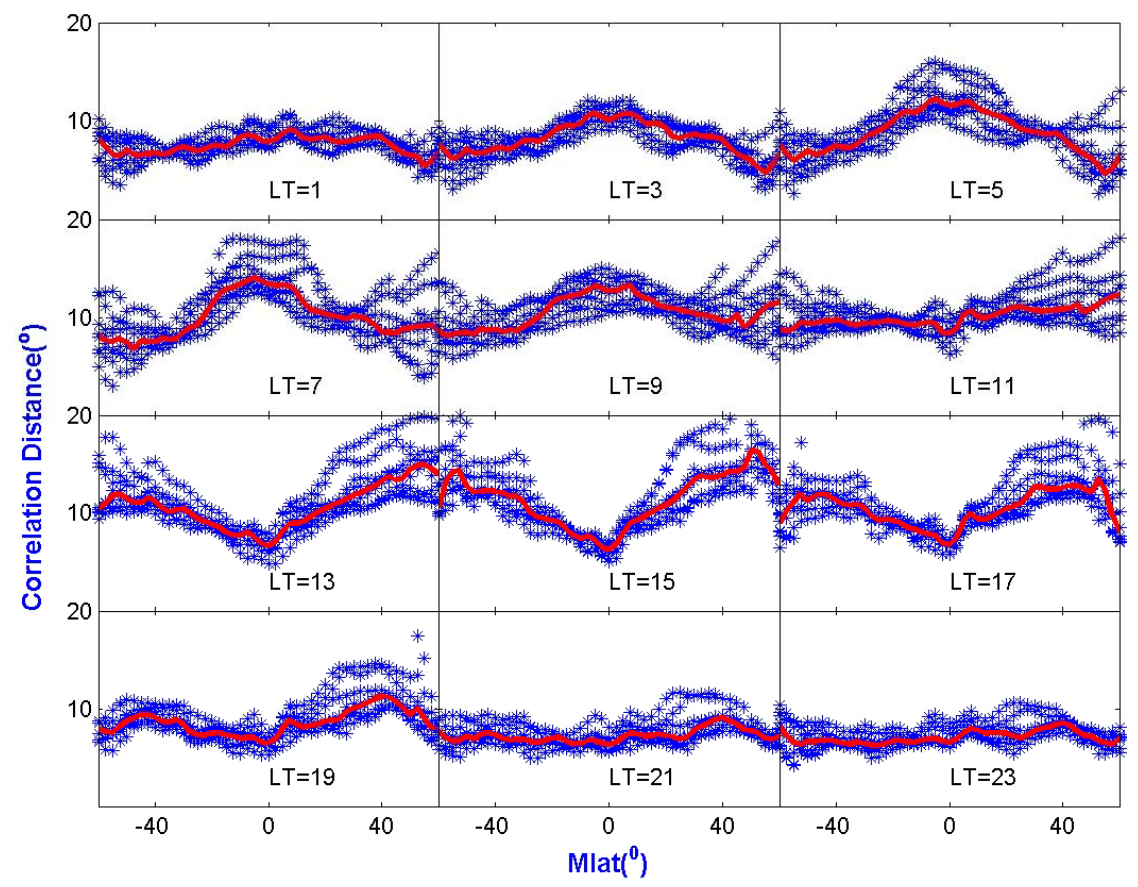

Fig. 3. (a) Latitude variations of meridional correlation distance for the 12 selected local times. Solid lines are the corresponding mean values of different seasons during 2000 and 2005.

obvious local time variations can be concluded. The vertical correlation distance is bigger in the daytime than in the night, which is consistent with that of the meridional correlation distance. The latitude and longitude variations of the vertical correlation distance cannot be investigated here, due to the choice of observations, and these will be studied in the future.

\section{Discussion}

4.1 The relative larger correlation between magnetic conjugate points

Relative larger correlations of TEC's day-to-day variabilities can be found between magnetic conjugate points from Fig. 2. Actually, the correlation between magnetic conjugate points has been found by several researchers. Yamamoto et al. (1995) observed electric fields fluctuations at magnetic conjugate points in both hemispheres simultaneously. They suggested that these fluctuations are caused by field-aligned currents which flow from the ionosphere in one hemisphere to the conjugate point in the other hemisphere. Geomagnetic conjugate point airglow observations indicate that plasma depletions elongate along the geomagnetic field lines (Otsuka et al., 2002). According to Rishbeth and Mendillo (2001), these factors, including electric field fluctuations and field-aligned plasma flows, can result in the day-to-day variability of the ionosphere. Even medium-scale traveling ionospheric disturbances (MSTID) at mid-latitude can also be observed at geomagnetic conjugate points simultaneously (Otsuka et al., 2004). It can be interpreted by the polarization electric field which maps along the magnetic field and moves the $\mathrm{F}$ region plasma upward or downward by $\boldsymbol{E} \times \boldsymbol{B}$ drifts, causing plasma density perturbations with structures mirrored in the Northern and Southern Hemispheres. Several sources of MSTID, such as atmospheric gravity waves that propagate upward from the lower atmosphere or are created in conjunction with auroral activity, auroral joule heating, and other weather events, may also cause ionospheric day-to-day variability (Otsuka et al., 2004; Rishbeth and Mendillo, 2001). So the geomagnetic conjugacy of the above factors may also result in the corresponding geomagnetic conjugacy of the electron densities' day-to-day variability. As indicated from Fig. 2b, the correlation coefficients between geomagnetic conjugate points have an obvious decrease around sunrise and sunset at the upper latitude $\left(60^{\circ}\right)$ and their values are bigger in the equinoxes than in the solstices. These variations can simply be interpreted by the deviation of the magnetic meridian from the geographical meridian. Because of the existence of this deviation, some geographic regions in one hemisphere, where the dip latitudes are high, will have an earlier sunrise (sunset) than that from the magnetic conjugate-points in the other hemisphere. The time delay of sunrise (sunset) between the magnetic conjugate points will result in the differences in the photoionization rates of the plasma. These differences are not notable at 


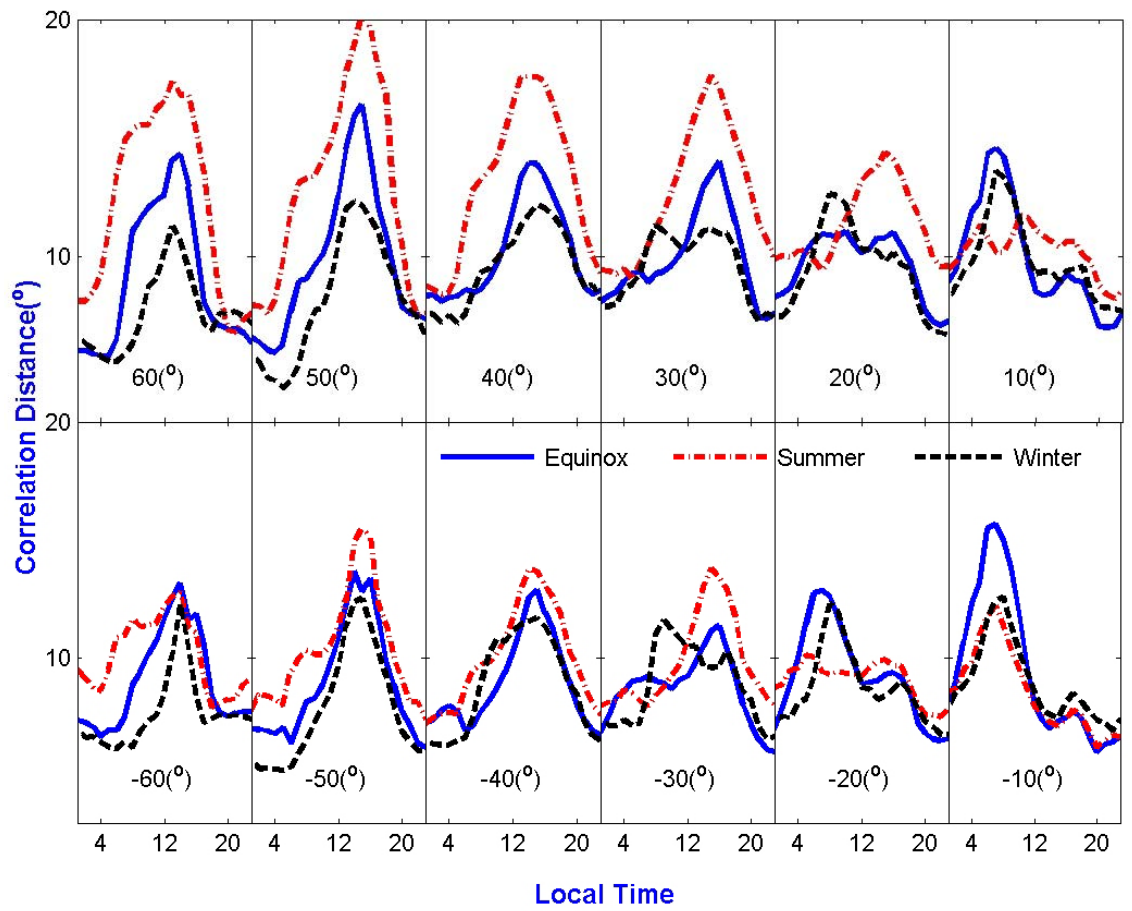

Fig. 3. (b) Local time variations of meridional correlation distance in 12 selected latitudes for equinox (solid lines), summer (dash-dot lines), and winter (dashed lines), respectively.

low latitudes because of the little dip latitude there and are more obvious during solstice than during equinox because of the lack of uniform sunshine during the solstice between both hemispheres. One evidence of the above theory is the presunrise ion temperature enhancement phenomena observed by ROCSAT-1 (Chao et al., 2003).

4.2 Variations of the correlation distance in three directions versus several factors

Many controlling factors, such as solar radiation, geomagnetic activity, and even seismic activity, may result in the ionospheric day-to-day variability (Rishbeth and Mendillo, 2001; Pulinets, 1998; Pulinets and Liu, 2004). Rishbeth and Mendillo (2001) have summarized almost all possible causes of the ionospheric F-layer variability and broadly divided them into four categories, which consist of solar ionizing radiation, solar wind and geomagnetic activity, neutral atmosphere, and electrodynamics. Of these factors, solar radiation, geomagnetic activity, and meteorological sources are most frequently discussed. It is recognized that the meteorological sources of the F-layer variability are comparable to the geomagnetic source and much larger than the solar component (Forbes et al., 2000; Fuller-Rowell et al., 2000; Mendillo et al., 2002; Rishbeth and Mendillo, 2001). Under geomagnetic quiet conditions, the variabilities of $\mathrm{N}_{\max }$ at high frequencies are mainly due to the meteorological influences (Forbes et al., 2000). As can be imaged, the day-to-day variabilities originating from different sources may have different spatial correlation scales. This is mainly because some sources are global (e.g., solar radiation) while some are localized (e.g., meteorological sources). Mendillo et al. (2002) found that the correlation scale size of meteorological disturbances may be around $2500 \mathrm{~km}$.

According to Forbes et al. (2000), ionospheric variability increases with magnetic activity at all latitudes and for both low and high frequency ranges, and the slopes of all curves increase with latitude. Thus, the responsiveness of the ionosphere to increased magnetic activity increases as one progresses from lower to higher latitudes. But they did not consider variations of in the variabilities versus local time and season. The local time and seasonal variations the ionospheric F-layer variabilities are statistically obtained by Araujo-Pradere et al. (2005) and Rishbeth and Mendillo (2001) by analyzing global ionosondes observations. A greater variability of $N m \mathrm{~F} 2$ at night than by day and in winter than in summer was shown. Enhanced auroral energy input and the lack of the strong photochemical control of the F2-layer at night are considered to be the cause of this phenomenon (Rishbeth and Mendillo, 2001). These variations of ionospheric variability indicate different dominating causes at different local times and latitudes, which may have different spatial correlation scales. These varied causes may result in the latitude and local time variations of the meridional correlation distance. The contrary latitude variations of 


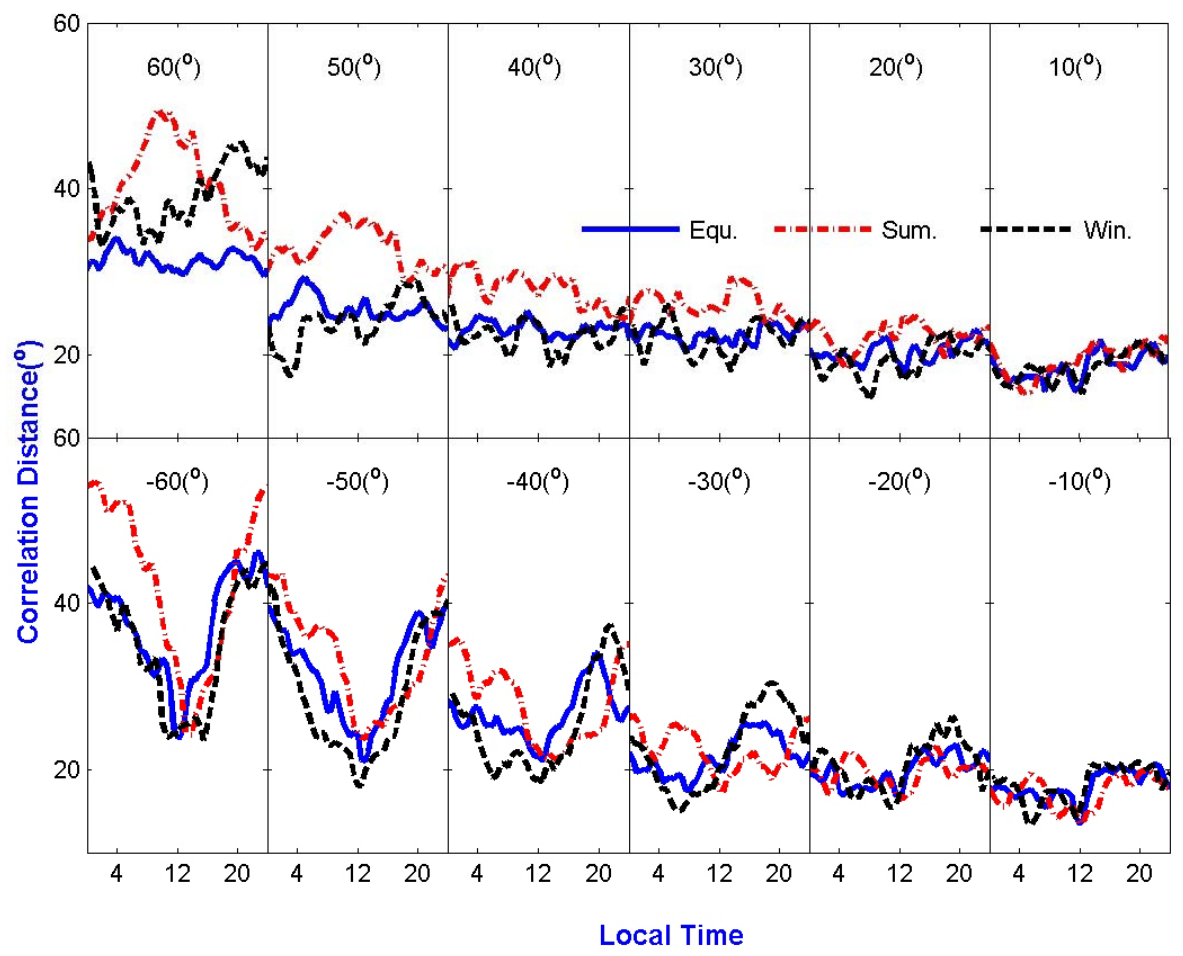

Fig. 4. Local time variations of zonal correlation distance for the selected latitudes for equinox (solid lines), summer (dash-dot lines), and winter (dashed lines), respectively.

the meridional correlation distance around sunrise may have a relationship with the time delay of sunrise at the higher dip latitude, as well as the special electrodynamics factors at low latitudes. These factors include the sensitivity of anomaly peak densities to day-to-day variations in F-region winds and electric fields driven by the E-region wind dynamo (Forbes et al., 2000) or the equatorial electrojet strength (Dabas et al., 2006). Considering the seasonal variation of ionospheric variability, the lowest variability was typically found in summer and the largest variability occurred in winter, with the equinox lying between the solstice extremes (Araujo-Pradere et al., 2005). From our results, the meridional correlation distance also has obvious seasonal variations in mid-latitudes in the Northern Hemisphere. This may be originated from the differences in the meteorological disturbances between summer and winter at mid-latitudes in the Northern Hemisphere (Yu et al., 2007). However, seasonal variations are not evident in low latitudes or in the Southern Hemisphere. The influences of data coverage in Southern Hemisphere can also not be eliminated. For the zonal correlation distance, the latitude variations can partly be interpreted by the decrease in the zonal circle with the increase in latitude. In Southern Hemisphere, the zonal correlation distance is greater in the nightside than in the dayside in all seasons. Further statistical analysis and modeling are needed to investigate this problem. For the mid-latitude, with the increase in altitude, the effect of the dynamical process becomes dominate. The effect of the dynamics process is more important at night than by day because of the absence of solar radiation at night. These variations in the control factors probably result in the altitude and local time variations of the vertical correlation distance of the electron density. However, further investigations are needed to address this issue.

\subsection{Influence of ionospheric storms on the spatial correla- tions}

During the geomagnetic storms, the ionosphere presents prominent disturbances with the increased solar and magnetospheric energy inputs, which is usually called an ionospheric storm. Since it was first discovered, the ionospheric storm has been studied extensively by the researchers all over the world. Many excellent reviews on this topic have been published in the last few years (e.g. Buonsanto, 1999; Mendillo, 2006; Prölss, 1995). In general, the patterns of ionospheric disturbances are different in different places (high, middle, and low latitude) and local times (day or night) during the same geomagnetic storm (Mendillo, 2006). It can generally be interpreted by the competitive results of different disturbed factors, including neutral wind, electric field, $\mathrm{O} / \mathrm{N} 2$, and etc.

Many researchers have studied the local time, latitude, and seasonal variations of ionospheric negative and positive 


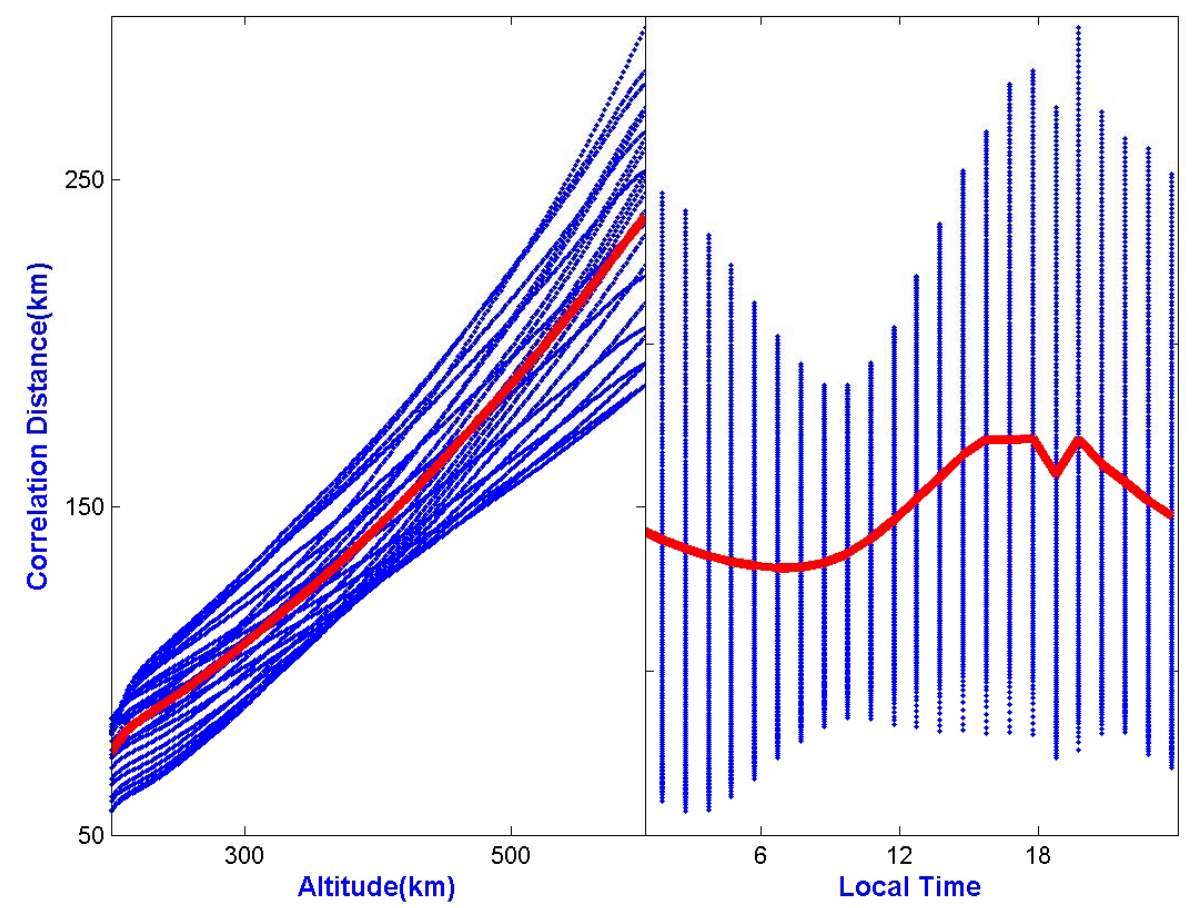

Fig. 5. Altitude and local time variations of the vertical correlation distance. The solid lines in the left panel are mean values of different local times and in the right panel are mean values of different altitudes.

storms by statistically analyzing the worldwide observations (Balan and Rao, 1990; Field and Rishbeth, 1997). In this paper, we did not consider the geomagnetic activity in the statistical processes. So the derived correlations may probably be influenced by the occurrence of an ionospheric negative or positive storm.

As indicated from Fig. 2b, the correlations of conjugate points between equinox hemispheres (February-April and August-October) are greater than that between the summer and winter hemispheres (May-July and November-January). Aside that the asymmetry of solar energy input into the two hemispheres is more obvious in solstices than in the equinoxes, the different occurrence rates of ionospheric negative or positive storms may also be an important cause. According to Field and Rishbeth (1997) and Prölss (1995), negative storm effects are observed to extend all the way from the polar region to the subtropics during summer, while during winter they are restricted to the higher latitude region, and positive storms are mainly observed in winter. But these differences are not obvious in the equinox hemispheres. The different phases of the ionospheric storms which occurred in the winter and summer hemispheres may decrease the correlation coefficients between the conjugate points. In addition, the difference in the motion directions of the midlatitude/high-latitude trough may also decrease this correlation. It is shown from Fig. 3b, in the mid-latitude of the Northern Hemisphere (from $40^{\circ}$ to $60^{\circ}$ ), the meridional cor- relation distance is larger in summer than in the equinox and larger in equinox than in winter. As described above, it mainly occures during negative storms in summer in the midlatitude (from $40^{\circ}$ to $60^{\circ}$ ), while in winter it is a transition area between a negative and positive storm. It is also shown in Fig. $3 b$ that the meridional correlation distance is larger in daytime than nighttime, except for the equatorial area. According to Balan and Rao (1990) and Prölss (1995), negative storms at middle latitude are usually observed to follow magnetic activity which occurred during the preceding night, while positive ionospheric storms are generally associated with magnetic activity beginning in the local daytime sector. These local time variations of ionospheric negative/positive storms might contribute to the differences in the meridional distance between the daytime and night in the higher latitude.

\section{Conclusions}

In this paper, the spatial correlations of ionospheric day-today variability are investigated, for the first time, by statistical analysis on GPS and Incoherent Scatter Radar observations in a global scale. The meridional correlations show significant $(>0.8)$ correlations in the latitudinal blocks of about 6 degrees on average. Relative larger correlations of TEC's day-to-day variabilities can be found between magnetic conjugate points. This phenomenon may be due to the geomagnetic conjugacy of several factors, such as electric field 
fluctuations, field-aligned plasma flows, and the polarization electric field, which are the causes of the ionospheric dayto-day variability. The correlation coefficients between geomagnetic conjugate points have an obvious decrease around sunrise and sunset at the upper latitude $\left(60^{\circ}\right)$ and their values are bigger between the winter and summer hemispheres than between spring and autumn hemispheres. The time delay of sunrise (sunset) between magnetic conjugate points with a high dip latitude is a probable reason. The asymmetry of the occurrence of a negative/positive storm in the solstices may also decrease the correlation.

In the daytime, the meridional correlation distance is bigger in the mid-latitude than in the low and equatorial latitudes, while no evident latitude variations around midnight are found. However, around sunrise, the meridional correlation distance is larger in equatorial area than at mid-latitude. The meridional correlation distance is larger in day time than night time, but the arisen time of the maximum is different at different latitudes. The zonal correlation distance increases with the increase in latitude in both hemispheres. Except for in the mid-latitude of the Southern Hemisphere (between $60^{\circ}$ and $-40^{\circ}$ ), where the zonal correlation distance is larger in the nightside than in the dayside, there is no distinct local time variation. The vertical correlation distance increases with the increase in altitude and is larger during the day than at night. These variations of the correlation distance of the ionospheric day-to-day variability versus different factors can generally be interpreted by the variations in the controlling factors, which may have different spatial scales. The influences of the occurrence of ionospheric storms may not be ignored. Further modeling and data analysis are needed to address this problem.

As indicated by Araujo-Pradere et al. (2005), it may be more accurate when considering the variability of the ionosphere in ionospheric modeling and forecasting (Stanislawska et al., 1996). Specific representation of the spatial correlation of ionospheric day-to-day variability may also be valuable in ionospheric modeling, especially in practical use for space weather. Furthermore, our results are useful for constructing background covariance matrix when assimilating observations into models, especially empirical models, by a 3DVAR or Kalman Filter method (Bust et al., 2004; Fuller-Rowell et al., 2006).

Acknowledgements. This work is supported by National Science Foundation of China (40636032, 40574071) and National important Basic Research Project (2006CB806306). Millstone Hill data were obtained through the Madrigal Database which is assembled and maintained by members of MIT Haystack. The Global Ionospheric Map data provided by the Jet Propulsion Laboratory are downloaded from the ftp site: ftp://cddis.gsfc.nasa.gov.

Topical Editor M. Pinnock thanks two anonymous referees for their help in evaluating this paper.

\section{References}

Araujo-Pradere, E. A., Fuller-Rowell, T. J., Codrescu, M. V., and Bilitza, D.: Characteristics of the ionospheric variability as a function of season, latitude, local time, and geomagnetic activity, Radio Sci., 40, RS5009, doi:10.1029/2004RS003179, 2005.

Balan, N. and Rao, P. B.: Dependence of ionospheric response on the local time of sudden commencement and the intensity of geomagnetic storms, J. Atmos. Terr. Phys., 52(4), 269-275, 1990.

Bradley, P. A. and Cander, L. R.: Proposed terminology for the classification and parameters for the quantification of variability in ionosphere morphology, Annals of Geophysics, 45(1), 97-103, 2002.

Bradley, P. A., Kouris, S. S., Stanislawska, I., Fotiadis, D. N., and Juchnikowski, G.: Day-to-day variability of IRI electron density height profile, Adv. Space Res., 34, 1869-1877, 2004.

Buonsanto, M. J.: Ionospheric storms - A review, Space Sci. Rev., 88, 563-601, 1999.

Bust, G. S., Coker, C., Coco, D., Gaussiran II T. L., and Lauderdate, T.: IRI data ingestion and ionospheric tomography, Adv. Space Res., 27(1), 157-165, 2001.

Bust, G. S., Garner, T. W., and Gaussiran, T. L.: Ionospheric Data Assimilation Three-Dimensional (IDA3D): A global, multisensor, electron density specification algorithm, J. Geophys. Res., 109, A11312, doi:10.1029/2003JA010234, 2004.

Chao, C. K., Su, S.-Y., and Yeh, H. C.: Presunrise ion temperature enhancement observed at $600 \mathrm{~km}$ low- and mid-latitude ionosphere, Geophys. Res. Lett., 30, 1187, doi:10.1029/2002GL016268, 2003.

Dabas, R. S., Sharma, N., Pillai, M. G. K., and Gwal, A. K.: Day-today variability of equatorial and low latitude F-region ionosphere in the Indian zone, J. Atmos. Sol. Terr. Phys., 68, 1269-1277, 2006.

Field, P. R. and Rishbeth, H.: The response of the ionospheric F2layer to geomagnetic activity: an analysis of worldwide data, J. Atmo. Sol. Terr. Phys., 59, 163-180, 1997.

Forbes, J. M., Palo, S. E., and Zhang, X. L.: Variability of the ionosphere, J. Atmo. Sol. Terr. Phys., 62, 685-693, 2000.

Fox, M. W.: A simple, convenient formalism for electron density profiles, Radio Sci., 29(6), 1473-1491, 1994.

Fotiadis, D. N. and Kouris, S. S.: A functional dependence of $f o \mathrm{~F} 2$ variability on latitude, Adv. Space Res., 37, 1023-1028, 2006.

Fuller-Rowell, T. J., Codrescu, M., and Wilkinson, P.: Quantitative modeling of the ionospheric response to geomagnetic activity, Ann. Geophys., 18, 766-781, 2000.

Fuller-Rowell, T., Araujo-Pradere, E., Minter, C., Codrescu, M., Spencer, P., Robertson, D., and Jacobson, A. R.: USTEC: A new data assimilation product from the Space Environment Center characterizing the ionospheric total electron content using real-time GPS data, Radio Sci., 41, RS6003, doi:10.1029/2005RS003393, 2006.

Gail, W. B., Prag, A. B., Coco, D. S., and Coker, C.: A statistical characterization of local mid-latitude total electron content, J. Geophys. Res., 98(A9), 15 717-15 728, 1993.

Huang, T. X.: Horizontal gradients and correlation coefficients in total electron content of the ionosphere, Chinese J. Geophys. (in Chinese), 26, 301-308, 1983.

Iijima, B. A., Harris, I. L., Ho, C. M., Lindqwister, U. J., Mannucci, A. J., Pi, X., Reyes, M. J., Sparks, L. C., and Wilson, B. D.: Automated daily process for global ionospheric total electron 
content maps and satellite ocean altimeter ionospheric calibration based on Global Positioning System data, J. Atmo. Sol. Terr. Phys., 61, 1205-1218, 1999.

Klobuchar, J. A., Doherty, P. M., and ElArini, M. B.: Potential ionospheric limitations to GPS Wide-Area Augmentation System (WAAS), Navigation, 42(2), 1995.

Mannucci, A. J., Wilson, B. D., Yuan, D. N., Ho, C. H., Lindqwister, U. J., and Runge, T. F.: A global mapping technique for GPSderived ionospheric total electron content measurements, Radio Sci., 33(3), 565-582, 1998.

Mendillo, M., Rishbetha, H., Roble. R. G., and Wroten, J.: Modelling F2-layer seasonal trends and day-to-day variability driven by coupling with the lower atmosphere, J. Atmos. Sol. Terr. Phys., 64, 1911-1931, 2002.

Mendillo, M.: Storms in the ionosphere: Patterns and processes for total electron content, Rev. Geophys., 44, RG4001, doi:10.1029/2005RG000193, 2006.

Miro Amarante, G., Cuteo Santamaria, M., Mosert de Gonzalez, M., Radicella, S. M., and Ezquer, R.: Day-to-day changes in experimental electron density profiles and their implications to IRI model, Adv. Space Res., 34, 1878-1886, 2004.

Nisbet, J. S., Tyrnov, O. F., Zintchenko, G. N., and Ross, W. J.: Limits on the Accuracy of Correction of Trans-ionospheric Propagation Errors by Using Ionospheric Models Based on Solar and Magnetic Indices and Local Measurements, Radio Sci., 16, 127133, 1981.

Otsuka, Y., Shiokawa, K., Ogawa, T., and Wilkinson, P.: Geomagnetic conjugate observations of equatorial airglow depletions, Geophys. Res. Lett., 29, 1753, doi:10.1029/2002GL015347, 2002.

Otsuka, Y., Shiokawa, K., Ogawa, T., and Wilkinson, P.: Geomagnetic conjugate observations of medium-scale traveling ionospheric disturbances at midlatitude using allsky airglow imagers, Geophys. Res. Lett., 31, L15803, doi:10.1029/2004GL020262, 2004.
Prölss, G. W.: Ionospheric F-Region Storms, in: Handbook of Atmospheric Electrodynamics, vol.2, edited by: H. Volland, chap. 8, pp. 195-248, CRC Press, Boca Raton, Fla., 1995.

Pulinets, S. A.: Seismic activity as a source of the ionospheric variability, Adv. Space Res., 22, 903-906, 1998.

Pulinets, S. A. and Liu, J. Y.: Ionospheric variability unrelated to solar and geomagnetic activity, Adv. Space Res., 34, 1926-1933, 2004.

Richmond, A. D.: Ionospheric electrodynamics using magnetic apex coordinates, J. Geomagn. Geoelectr., 47(2), 191-212, 1995.

Rishbeth, H.: How the thermospheric composition affects the ionospheric F2-layer,J. Atmos. Sol. Terr. Phys., 60, 1385-1402, 1998.

Rishbeth, H. and Mendillo, M.: Patterns of F2-layer variability, J. Atmo. Sol. Terr. Phys., 63, 1661-1680, 2001.

Rush, C. M.: An ionospheric observation network for use in shortterm propagation predictions, Telecommun. J., 43(8), 544-549, 1976.

Saito, A., Iycmori, T., Sugiura, M., Maynard, N. C., Aggson, T. L., Brace, L. H., Takeda, M., and Soicher, H.: Spatial Correlation of Transionospheric Signal Time Delays, IEEE Transactions on Antennas and Propagation AP-26, 3, 1978.

Stanislawska, I., Juchnikowski, G., and Cander, Lj. R.: Kriging method for instantaneous mapping at low and equatorial latitudes, Adv. Space Res., 18(6), 217-220, 1996.

Yamamoto, M.: Conjugate occurrence of the electric field fluctuations in the nighttime midlatitude ionosphere, J. Geophys. Res., 100(A11), 21 439-21 451, 1995.

Yu, X., Wan, W., Liu, L., Yue, X., and Xu, G.: Correlation distance of $\mathrm{NmF}$ 's day-to-day variability in Europe, Chinese J. Geophys., (in Chinese), 50(5), 1283-1288, 2007. 